\title{
ОСОБЕННОСТИ РЕГУЛИРОВАНИЯ РИСКОВ УПРАВЛЕНИЯ В СЛОЖНОЙ МНОГОУРОВНЕВОЙ СОЦИАЛЬНО-ЭКОНОМИЧЕСКОЙ СИСТЕМЕ (СМСЭС)
}

\author{
(C) 2019 Безденежных Вячеслав Михайлович \\ доктор экономических наук, профессор кафедры Анализа рисков и экономической безопасности \\ Финансовый университет при Правительстве РФ, Россия, Москва \\ E-mail:savrula@gmail.com
}

(C) 2019 Ализада Джамшид Физули

аспирант

Финансовый университет при Правительстве РФ, Россия, Москва

E-mail: alizadedzhamshid@gmail.com

Происходящие в России и мире в экономических структурах технологические и структурные преобразования актуализировали проблему обеспечения экономической безопасности и эффективности реализации крупных и масштабных проектов и госпрограмм, как в практическом, так и в теоретическом отношении. Система управления реализацией госпрограмм имеет сложную многоуровневую структуру, в которой с различными функциями управления и исполнения принимают участие многие организации. В статье исследуются основные сущностные признаки и особенности сложных сетевых образований как объектов государственного регулирования с точки зрения образования угроз и рисков безопасности функционирования, а также ключевые особенности развития национальной модели системного управления с учетом рисков.

Ключевые слова: Система управления реализацией госпрограмм, обеспечение экономической безопасности, факторы образования угроз и рисков безопасности, сложная многоуровневая социально-экономическая система (СМСЭС).

Череда крупномасштабных скандалов, потрясших крупнейшие финансово-банковские корпорации мира (США, Великобритании, Кореи, Японии, Сингапура и др.) в различных отраслях экономики в последние десятилетия, заставили критически посмотреть на риски управления сложными многоуровневыми социально-экономическими системами (СМСЭС), на многие до того незыблемые правила и процедуры, состояние управленческой морали и этики. Трансформационные процессы в российской экономике, направленные на формирование нового типа хозяйствующих субъектов - организаций как предпринимательских структур, в которых все риски развития ложатся не на государство через его представителей, а на собственников и менеджеров хозяйственных структур, усугубились под воздействием глобальных процессов. Как подчеркивает М.А. Эскиндаров, «... сейчас Россия переживает становление очередной системы хозяйствования, которой предстоит функционировать значительный отрезок времени. Одновременно создаются присущие ей организационно-хозяйственные формы (экономические институты), определяющие новые «правила игры», призванные внести определенный порядок в систему взаимоотношений рыночных субъектов, в повседневную хозяйственную жизнь...». И далее,- «возникающие хозяйственные структуры появляются с нарушением формальных правил, сложившейся нормативно-правовой базы, что, несомненно, будет вести к конфликтам и обеспечивать противоречивое развитие складывающихся систем и форм хозяйствования [9]. Складывающимся так называемым «сетевым образованиям»*, т.е. новым системам взаимодействия по организации и управлению, предстоит подтвердить свою совместимость с задачами экономического воспроизводства в рамках российской хозяйственной системы в целом. Это касается всех хозяйствующих субъектов от сетевых ассоциаций предприятий малого бизнеса, более эффективно реализующих свою экономическую и социаль-

\footnotetext{
* При употреблении в исследованиях понятия «сетевые образования» не в американском или европейском (английском) законодательстве, а в российской практике и научной литературе пока нет сложившейся понятийной однозначности даже при переводе термина на русский язык. Далее будут показаны особенности авторской трактовки этого понятия.
} 
ную сущность (выход на новые рынки, создание новых рабочих мест, использование дополнительных ресурсов человеческого капитала, гибкую адаптацию к меняющимся условиям рынка, выживания в условиях кризиса и преодоление экономического спада и д.) только при взаимодействии и интегрированности в различных формах (местного, отраслевого, историко-культурного, гендерного, профессионального и пр.) объединения и координации. До формирования сетевых ассоциаций масштабных проектов и организаций, охватывающих несколько регионов и даже стран (государственных, национальных, целевых программ, крупных национальных проектов (например, строительство Крымского моста, трассы Таврида, космодрома «Восточный» и др.) и международных проектов (например, Южный и Северный поток - 1 ; 2 , «Шелковый путь» и др.).

Происходящие в России и мире в экономических структурах технологические и структурные преобразования актуализировали проблему обеспечения экономической безопасности и эффективности реализации проектов, как в практическом, так и в теоретическом отношении. В работе конкретизируется цель, в которой объектом исследования служат социальноэкономические отношения, формирующие при выполнении государственных программ и образующие риски их реализации на мезо-уровне государственного регулирования как основного звена в цепочке управления государственными программами как сложными многоуровневыми социально-экономическими системами (СМСЭС).

Можно выделить, исходя из установленной цели и задач данного исследования, следующие основные сущностные признаки и особенности указанных сложных сетевых образований как объектов государственного регулирования с точки зрения факторов образования угроз и рисков безопасности функционирования:

- Наличие нового вида собственников, которые отделены от управления собственностью Взаимоотношения между участниками определяются природой и размерами объединяемого в единую систему капитала. Чем выше уровень концентрации, тем больше размер капитала, тем в большей мере проявляется отчужденность по отношению к собственности. Это способствует переносу и размыву ответственности высше- го менеджмента за их координацию и исполнение в связи с не принудительным характером исполнения хозяйственных решений «... на основе свободной дисциплины всех участников» и соответственно, росту рисков принятия и реализации этих решений.

- Формирование механизмов делегирования полномочий. В обычных органах государственного регулирования все довольно жестко регламентировано, тогда как в СМСЭС существуют несколько уровней и центров принятия решений и, соответственно, формируются дополнительные риски принятия решений. При этом возникают новые конфликты и необходимость баланса интересов всех заинтересованных участников реализации госпрограмм.

- Наличие в ее составе СМСЭС большого состава организаций (юридических лиц), которые занимаются диверсифицированными видами бизнеса на микроуровне регулирования. Появление дополнительных рисков связано с развитием в ходе системного формирования процессов перераспределения производства, при которых в российской практике отмечено нарушение обычной или традиционной последовательности развития хозяйственных и инфраструктурных форм. Более совершенные (современные) формы часто сталкиваются с архаичными и устаревающими с низким уровнем организации, неподготовленностью старого персонала к инновациям и лихорадочной активностью нового менеджмента, озабоченного личным обогащением. Организационно-технологические конфликты порождают скрытые угрозы реализации госпрограмм и безопасности системы в целом.

- Занятие СМСЭС на рынке (в определенной его нише) доминирующего положения группы однородных структур по характеру деятельности в сфере приложения ресурсов (включая административный), что позволяет не только определять объемы производства и цены, но и выработать общую рыночную стратегию. При этом формируется также дополнительная стоимость корпоративного бренда, имеющего заметную долю в общей капитализации корпорации (достигающая 30-40\% и измеряемая сотнями миллионов долларови даже десятками миллиардов и более долларов*), и появляются дополнительные угрозы и риски функционирования СМСЭС.

- Большие (в формате доли рынка) размеры

\footnotetext{
* Американская корпорация Apple по данным агентства Millward Brouwn имеет бренд, оцениваемый в $\$ 153$ млрд., опередив корпорации Google, IBM, Microsoft и China Mobile. MK, 10 мая 2011 г. В сотню мировых брендов вошли российские нефтяные компании ... и впервые, Сбербанк.
} 
бизнеса и как следствие большое число работников (свыше 4-5 тыс. чел.). Это усложняет структуру управления, порождая дополнительные риски.

- Важна роль имиджа в подобных проектах, поскольку, будучи крупной и влиятельной, госпрограмма должна быть привлекательной для общества и, прежде всего, населения как основного представителя стейкхолдеров.

- Очень большое значение имеет единая высокая общесистемная корпоративная культура управления, определенные формальные и неформальные правила поведения и этики сотрудников, традиции, кодекс корпоративных норм и правил выполнения работ.

- Будучи крупным социально-экономическим институтом управления, СМСЭС должна заниматься стратегическим контроллингом (планированием, контролем и мониторингом), то есть смотреть на несколько лет вперед, распределяя свои ресурсы и планируя цели, показатели развития.

- Как подчеркивается в ряде исследований [8], в выработке и принятии хозяйственных решений в рамках сложной системы велика доля неопределенности и субъективизма, порождающая дополнительные угрозы и риски, так как они должны отражать интересы различных субъектов со сложившимися организацией и руководством. Осуществление управления в сложной многоуровневой организации характеризуется следующими признаками, формирующими факторы угроз и образования рисков внешней среды и функционирования внутренней структуры:

- Утилитаризмом принятых решений;

- Целенаправленностью действий;

- Экономической «эмпатией»*;

- Добровольным подчинением корпоративным (системным) управляющим практикам и нормам;

- Ограниченной конкуренцией в рамках системной структуры.

При наличии уже наработанных базовых государственных документов и накопленного опыта можно проектировать систему управления корпоративного типа на уровнях сложной различной конфигурации, задавая, таким образом, определенные ориентиры и форматы для всей российской экономики. При этом в России в настоящее время формально присутствуют компоненты всех традиционных моделей формирования управления сетевых образований: относительно распыленная собственность, явная и устойчивая тенденция к концентрации собственности и контроля, элементы перекрестных владений и формирование сложных корпоративных структур разного типа не только третьего, но даже пятого колена [5] (но при отсутствии тяготения к какому-либо типу).

В России среди ключевых особенностей развития национальной модели системного управления 90-х г.г. и начала первого десятилетия, кроме уже отмеченных чуть выше, необходимо выделить приведенные в таблице 1.

Учитывая сущностные функции сетевых образований, задачи управления (в том числе и эффективность управления и экономической безопасностью системы в целом) включают двуединый процесс управления взаимодействием системного образования (со структурой различной конфигурации и степени связности): с внешней средой и управления внутри структуры системного образования. Эффективность управления должна основываться на принципах экономического роста: внедрять современные методы и стили управления, инновационные процессы [2].

При реализации программ для повышения эффективности управления реализацией госпрограмм предусмотрен механизм согласования изменений и корректировки. Портал государственных программ www.programs.gov.ru с 1 июля 2015 г. перешел к инициативному согласованию государственных программ Российской Федерации. Процедура инициативного согласования осуществляется в электронном виде с использованием указанного Портала государственных программ и является частью сетевой системы управления реализацией госпрограмм. В инициативном согласовании принимают участие все федеральные органы исполнительной власти, а также заинтересованные организации.

\footnotetext{
* «Эмпатия» в психологии - эмоциональная восприимчивость - фундаментальная характеристика эмоционального поведения, свойственного человеку. Эмоциональная восприимчивость проявляется в частоте, разнообразии и интенсивности «подключения» энергии эмоций к реагированию на значимые для личности воздействия. В хозяйственной деятельности это проявляется в корпоративном реагировании (восприятии и терпимости) на воздействия рынка и внутренние изменения. Понятие введено М.А. Эскиндаровым.
} 
Таблица 1. Особенности российской модели управления СМСЭС

\begin{tabular}{|c|c|c|}
\hline № $\Pi \backslash \Pi$ & Особенности российской модели управления СМСЭС & Динамика изменений \\
\hline 1. & $\begin{array}{l}\text { перманентный процесс перераспределения собственности в сетевых } \\
\text { структурах, ведущий к концентрации капитала и контроля }\end{array}$ & Постепенные изменения \\
\hline 2. & Инсайдерский характер собственности &..-- \\
\hline 3. & $\begin{array}{l}\text { сокращение количества мелких акционеров и увеличение долей круп- } \\
\text { ных акционеров }\end{array}$ &..- \\
\hline 4. & сохранение относительной распыленности собственности &..-- \\
\hline 5. & $\begin{array}{l}\text { специфические мотивации многих инсайдеров (менеджеров и крупных } \\
\text { акционеров), связанные с контролем финансовых потоков и «выводом» } \\
\text { активов }\end{array}$ &..-- \\
\hline 6. & $\begin{array}{l}\text { исполнительные директора обладают огромной властью в корпорациях, } \\
\text { большей, чем лишь контроль над повседневными операциями }\end{array}$ &..-- \\
\hline 7. & $\begin{array}{l}\text { слабая или нетипичная роль традиционных «внешних» механизмов } \\
\text { системного управления }\end{array}$ & $\begin{array}{l}\text { Рынок ценных бумаг } \\
\text { (особенно рынок акций), } \\
\text { механизм банкротства. } \\
\text { рынок корпоративного } \\
\text { контроля активно транс- } \\
\text { формируются }\end{array}$ \\
\hline 8. & $\begin{array}{l}\text { советы директоров играют, главным образом, пассивную роль и вклю- } \\
\text { чают в себя несколько акционеров-аутсайдеров }\end{array}$ & $\begin{array}{l}\text { Сейчас ситуация меня- } \\
\text { ется }\end{array}$ \\
\hline 9. & $\begin{array}{l}\text { общие собрания акционеров фактически отстранены от управления } \\
\text { обществом }\end{array}$ &..-- \\
\hline 10. & $\begin{array}{l}\text { значительная доля государства в акционерном капитале и вытекающие } \\
\text { проблемы управления и контроля }\end{array}$ & Ситуация сохраняется \\
\hline 11. & Слабость институциональных инвесторов & $\begin{array}{l}\text { В настоящее время } \\
\text { ситуация несколько } \\
\text { изменяется }\end{array}$ \\
\hline 12. & $\begin{array}{l}\text { Элементы перекрестных владений и формирование сложных корпора- } \\
\text { тивных структур разного типа при отсутствии тяготения к какому-либо } \\
\text { типу }\end{array}$ & Ситуация сохраняется \\
\hline 13 & Отсутствие адекватного финансирования и эффективного мониторинга &..-- \\
\hline 14. & $\begin{array}{l}\text { Активная роль региональных властей как самостоятельного субъекта } \\
\text { корпоративных отношений }\end{array}$ & $\begin{array}{l}\text { Регион - субъект, } \\
\text { действующего в рамках } \\
\text { конфликта интересов - } \\
\text { как собственник, как } \\
\text { регулятор через адми- } \\
\text { нистративные рычаги } \\
\text { воздействия, как хозяй- } \\
\text { ствующий субъект }\end{array}$ \\
\hline 15. & $\begin{array}{l}\text { Неэффективный и/или выборочный (политизированный) государствен- } \\
\text { ный инфорсмент }\end{array}$ & $\begin{array}{l}\text { При сравнительно раз- } \\
\text { витом законодательстве } \\
\text { в области защиты прав } \\
\text { акционеров }\end{array}$ \\
\hline
\end{tabular}

Источник: составлено авторами.

Все предложения по доработке государственных программ, представленные в рамках инициативного согласования, поступают на рассмотрение в федеральный орган исполнительной власти, являющийся ответственным исполнителем государственной программы.

По результатам рассмотрения поступивших предложений ответственный исполнитель принимает решение об их принятии либо отклонении.

Даже отклоненные инициативы представ- ляются ответственным исполнителем вместе с государственной программой в Правительство Российской Федерации и потенциально могут быть рассмотрены и поддержаны на более поздних стадиях рассмотрения проекта государственной программы [10].

Система управления реализацией госпрограмм имеет сложную многоуровневую структуру, в которой с различными функциями управления и исполнения принимают участие многие организации (рис. 1). 


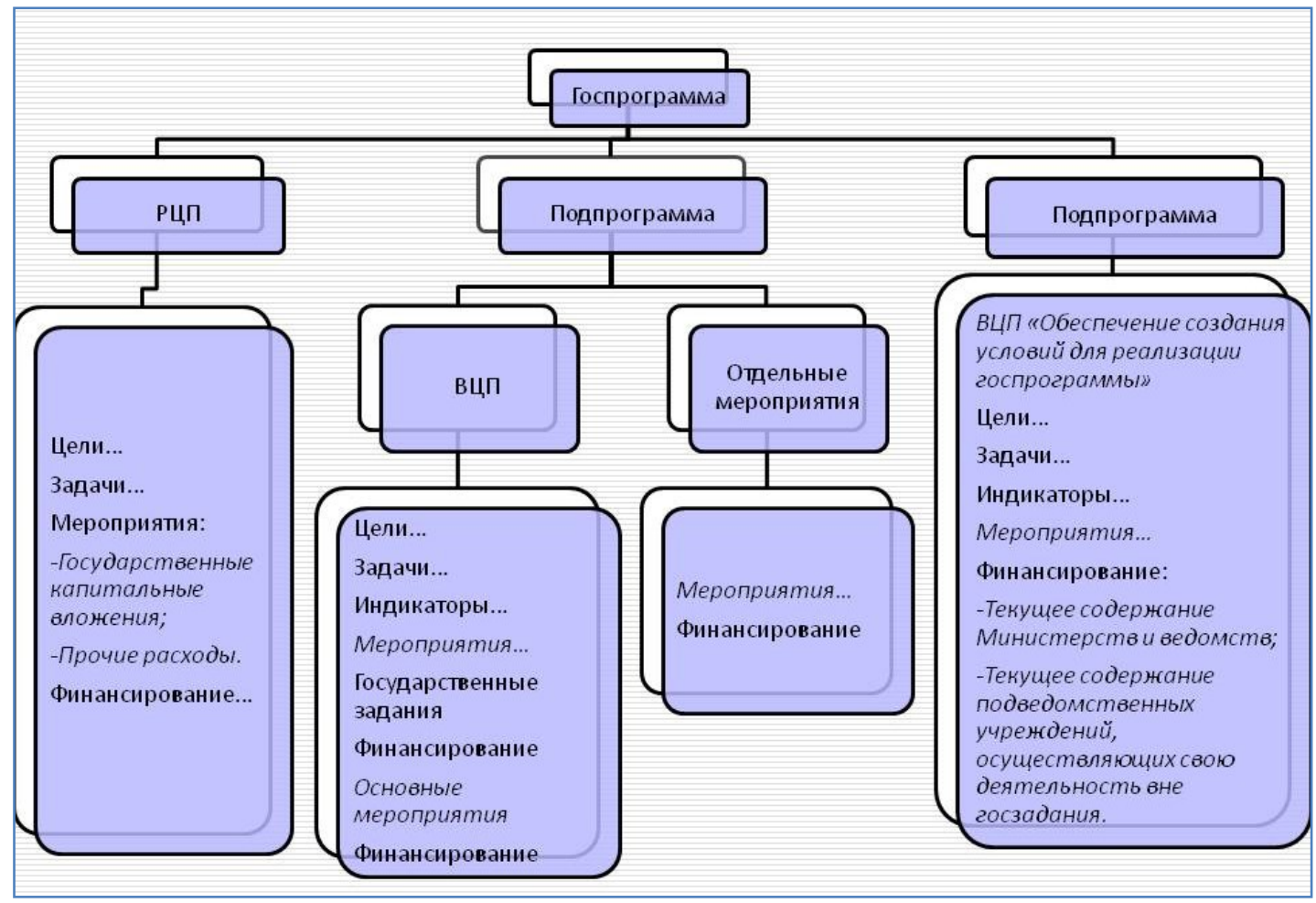

Puc. 1. Обобщенная структура государственной программы.

Источник: www.programs.gov.ru

Можно выделить несколько уровней регулирования и контроля исполнения госпрограмм.

Федеральный макроуровень управления реализацией может включать федеральный орган исполнительной власти, другие федеральные структуры, включая Минэкономразвития, ответственное за согласование и изменения госпрограмм, а также международные государственные и частные компании (например, проекты «Шелковый пояс», «Северный поток» - 1, 2 и др.).

Мезо-уровень реализации госпрограмм может включать органы региональной исполнительной власти и руководителей крупных межрегиональных проектов (например, строительство Крымского моста).

Микроуровень системы управления реализацией госпрограмм может включать органы исполнения государственных заданий госпрограмм учреждениями, организациями, корпорациями различного правового статуса, включая зарубежные организации.

В целом систему управления рисками реализации госпрограмм с учетом рисков их выполнения составляет обширный набор элементов, включая:

- документы стратегического проектного планирования;
- ресурсы, необходимые для управления реализацией госпрограмм;

- сотрудников управления всех уровней, ответственных за выполнение отдельных разделов программ и программу в целом,

- информационную базу данных, необходимых для реализации госпрограмм,

- скоординированную систему мониторинга, документирования и отчетности реализации госпрограмм всех уровней, включая отчетность в системе управления рисками реализации,

- систему согласования и изменения содержания госпрограмм в ходе их реализации,

- систему управления эффективностью выполнения госпрограмм, включая методы оценки эффективности, методы оценки рисков реализации отдельных разделов и программ в целом.

В целом, система управления рисками реализации госпрограмм является сложной многоуровневой социально-экономической системой (СМСЭС), охватывающей от десятков до сотен участников госпрограмм и более, ее пространственными границами являются границы полномочий участников в части выполнения программ, а временными границами - время реализации госпрограмм (с учетом корректировок). 


\section{Библиографический список}

1. Авдийский В.И. Теневая экономика и экономическая безопасность государства / В.И. Авдийский, В.А. Дадалко.-М.: «Творческая мастерская», 2009.

2. Аничкина О.А., Капустина Н.В. Особенности становления и развития малых организаций пищевой промышленности [Текст] / Аничкина О.А., Капустина Н.В. // «Экономика и предпринимательство» 2014. № 6(47). с.624-628

3. Безденежных В.M. Управление устойчивостью сложных экономических систем на основе их реструктуризации. Монография.-М.: Альта», 2006.

4. Глазьев С. Основа обеспечения экономической безопасности - реформаторский курс / С. Глазьев // РЭЖ. 1997. - № 1.- С. 3-19.

5. Долгопятова Т.Г. Собственность и корпоративный контроль в российских компаниях в условиях активизации интеграционных процессов // «Российский журнал менеджмента». - 2004. - Т. 2, № 2. - С. 3-26.

6. Комплексная методика диагностики социально-демографической безопасности региона / Под ред акад. РАН А.И. Татаркина, д.э.н. А.А. Куклина.-Екатеринбург: Ин-т экономики УрО РАН, 2007.

7. Клепач А., Кузнецов П., Крючкова П. Корпоративное управление в России в 1995-96 г. (от предприятия советского типа к фирме, контролируемой менеджерами) // «Вопросы экономики»._-1996.- № 12._- С. $73-87$.

8. «Эффективный экономический рост - главное условие выхода из социально-экономического кризиса» (апрель 1999). Материалы конференции. \\ Под редакцией Т.В. Чечелевой, Л.Б. Мамоновой.- М.: Финансовая академия, 1999.

9. Эскиндаров М.А. Развитие корпоративных отношений в современной российской экономике.- М., Республика, 1999.

10. Порядок разработки, реализации и оценки эффективности государственных программ Российской Федерации, утвержденного постановлением Правительства Российской Федерации от 02 августа 2010 года № 588.

11. Bernulli D. Exposition of a New Theory on the Measurement of Risk. // Econometrica, 1954, vol. 22, p. 23-36. 